\title{
Impact of body mass index on duplex parameters of cranial vessels among the Egyptian population
}

\author{
Tarek A. Rageh, Mostafa Ghazally ${ }^{*}$ and Khaled O. Mohamed
}

\begin{abstract}
Background: Obesity is a major health problem that affects different vascular systems, including cerebrovascular circulation. Carotid duplex is the best screening tool for early diagnosis of cerebrovascular changes in relation to different risk factors including obesity. The present study aims to evaluate the effect of body mass index on the parameters of extracranial vessels in healthy subjects using vascular duplex ultrasonography.

Results: The intimal medial thickness in the common carotid is found to increase as the body mass index and body weight increase (directly related), with this increase being significant ( $P$-value $<0.05)$.

Conclusion: These findings indicate that increase in body mass index can adversely affect duplex parameters of the common carotid artery.

Clinical trial registration NCT03252652. Registered August 16th 2017

Keywords: Carotid duplex, Obesity, Body mass index, Intimal medial thickness
\end{abstract}

\section{Background}

Arterial diseases, mostly due to atherosclerosis are the most prevalent disease currently worldwide. Atherosclerotic arterial diseases are usually silent and progressive and can lead to stable or slowly progressive clinical syndromes [1]. Diabetes, hypertension, and previous history of stroke have increased risk for cerebrovascular diseases, stroke, and cognitive decline. Body mass index (BMI) is being increasingly recognized as a risk factor for stroke, cardiovascular disease, and cognitive decline, in addition to traditional risk factors [1].

About $30-60 \%$ of strokes are caused by atherosclerotic disease involving the extracranial carotid arteries usually within $2 \mathrm{~cm}$ of the carotid bifurcation [2]. Sonography is unique among vascular imaging procedures in that it can assess plaque composition. Sonography detected plaque

\footnotetext{
*Correspondence: mostafa_hamdy2222@yahoo.com; mostafaghazally1992@gmail.com

Neurology Department, Faculty of Medicine, Assiut University, Asyût 71526, Egypt
}

characteristics may have prognostic value and may be useful for selection of medical and surgical therapy [3].

Overweight represents one of the major health problems. Its prevalence is increasing rapidly worldwide, with estimates of over 1.9 billion adults were overweight and over 650 million were obese worldwide $[4,5]$. The recent reports showed that the prevalence is $74-86 \%$ among women and $69-77 \%$ among men in the Arab countries, with Egypt being one of the most prevalent countries [6]. Fundamental causes of the current obesity epidemic are associated with sedentary lifestyles, increased consumption of energy-dense foods high in saturated fats and sugars, and physical activity. Clinically, obesity is defined by measurements of body mass index [7] or waist circumference and waist-to-hip ratio [8]. Body mass index (BMI) is defined as a person's weight in kilograms divided by the square of his/her height in meters $\left(\mathrm{kg} / \mathrm{m}^{2}\right)$.

Obesity is associated with cardiovascular disease, stroke and vascular remodeling [9]. Vascular remodeling is an active process of structural change that involves 
series of consecutive cell death, proliferation, and extracellular matrix degradation. This will contribute to elevated systemic vascular resistance and enhance plaque erosion and rupture, predisposing to future vascular events [10].

Vascular duplex ultrasonography is a useful, cheap, and available diagnostic tool for assessing cranial vascular disease. Duplex US (DUS) can be highly reliable with proper technique, without the risk of radiation as in other imaging modalities, is well tolerated by all patients including those who are claustrophobic in MRI machines, and has much fewer risks compared to conventional angiography studies.

The present study aims to evaluate the influence of body mass index on parameters of cranial vessels by using vascular duplex ultrasonography.

\section{Methods}

\section{Patient population}

The study included 100 healthy subjects (by history and examination had no symptoms or signs suspicious of physical illness), 56 females and 44 males, their ages range from 20 to 60 years, presented with non-vascular related complaints at neurology and psychiatry clinic at our university hospital during the period from December 2017 to July 2019. The study was approved by the IRB in our university and all patients were enrolled after written consent.

Number of subjects included in normal weight group is 54 , while the number of patients included in overweight group is 46 (people with BMI 25-29.9 is 36 while number of subjects with BMI more than 30 is 10). Patients with diabetes, hypertension, hyperlipidemia, hyper uricemia either on treatment or recently diagnosed and those on vaso-active drugs, were excluded from our study.

\section{Imaging}

All subjects had extra-cranial carotid duplex ultrasonography using a high-resolution color duplex, Philips Envisor C Ultrasound System, with L 12-3 MHz linear transducer probe, San Jose, CA, USA. Equipment gain and display settings were optimized while imaging vessels with respect to depth, dynamic range and focal zones. Color flow Doppler was added to supplement B-mode images with proper color scale to demonstrate areas of high flow and color aliasing. Power Doppler was used to validate low flow states or occlusions. Small cursor sample size was employed and positioned parallel to the vessel wall and/or direction of blood flow. Velocities were measured using spectral Doppler angle of $60^{\circ}$ or less, setting gain to allow a spectral window and reducing artifact.
Subjects were examined in supine positions with their heads slightly elevated and turned to the contralateral side. The site of the carotid segments to be studied was determined according to the distance from the flow divider as follows: common carotid artery (CCA) $1 \mathrm{~cm}$ segment proximal to the dilation of the carotid bulb; $1 \mathrm{~cm}$ segment proximal to the flow divider Carotid bifurcation (CBIF); and $1 \mathrm{~cm}$ segment in the internal branch distal to the flow divider (ICA) [11]. IMT measurements were taken from the leading edges of the far wall echoes while luminal diameter (LD) measurements were taken from the leading edge of the near wall intima-lumen echo to the leading edge of the echo from the far wall lumenintima interface (the same location as the IMT measurements) [12]. Both sides of the carotid arteries were examined with longitudinal scans. When an optimal longitudinal image was obtained, the image was magnified and frozen and the IMT and LD were measured. A transverse scan was occasionally performed when needed.

An artery was classified as being affected by plaque if there was a focal wall thickening at least $50 \%$ greater than that of the surrounding vessel wall or a localized region with CIMT greater than $1.5 \mathrm{~mm}$ that did not uniformly involve the whole left or right carotid artery with or without a flow disturbance [13].

\section{Results}

\section{Statistical analysis}

All statistical analyses were performed with SPSS 24.0 (SPSS Inc., Chicago, IL. USA). Continuous variables were expressed as mean \pm SD using the Student's $t$-test (normally distributed) for paired values. Differences were considered significant at $P<0.05$.

\section{Subject population}

Subjects' characteristics are shown in Table 1.

Number of subjects included in normal weight group is 54 , while the number of patients included in overweight group is 46 .

The intimal medial thickness in the common carotid was found to increase as the body mass index and body weight increase (directly related) as shown in Figs. 1 and 2 , with this increase being significant $(P$ value $<0.05)$.

Table 1 Demographic data and patient characteristics

\begin{tabular}{lcccc}
\hline & Male $(\boldsymbol{n}=\mathbf{4 4})$ & Female $(\boldsymbol{n}=\mathbf{5 6})$ & Total & $\boldsymbol{P}$ value \\
\hline Age & $33.8 \pm 12.2$ years & $36.5 \pm 12.8$ years & $33.5 \pm 12.5$ years & 0.1 \\
Weight & $83.7 \pm 15.7 \mathrm{~kg}$ & $71.6 \pm 10.5 \mathrm{~kg}$ & $77.5 \pm 14.5 \mathrm{~kg}$ & 0.06 \\
Height & $173.7 \pm 5.0 \mathrm{~cm}$ & $165.6 \pm 4.0 \mathrm{~cm}$ & $169.5 \pm 6.5 \mathrm{~cm}$ & 0.08 \\
BMl & $27.7 \pm 0.4 \mathrm{~kg} / \mathrm{m}^{2}$ & $31.1 \pm 3.1 \mathrm{~kg} / \mathrm{m}^{2}$ & $26.8 \pm 3.9 \mathrm{~kg} / \mathrm{m}^{2}<0.0001$ \\
\hline
\end{tabular}



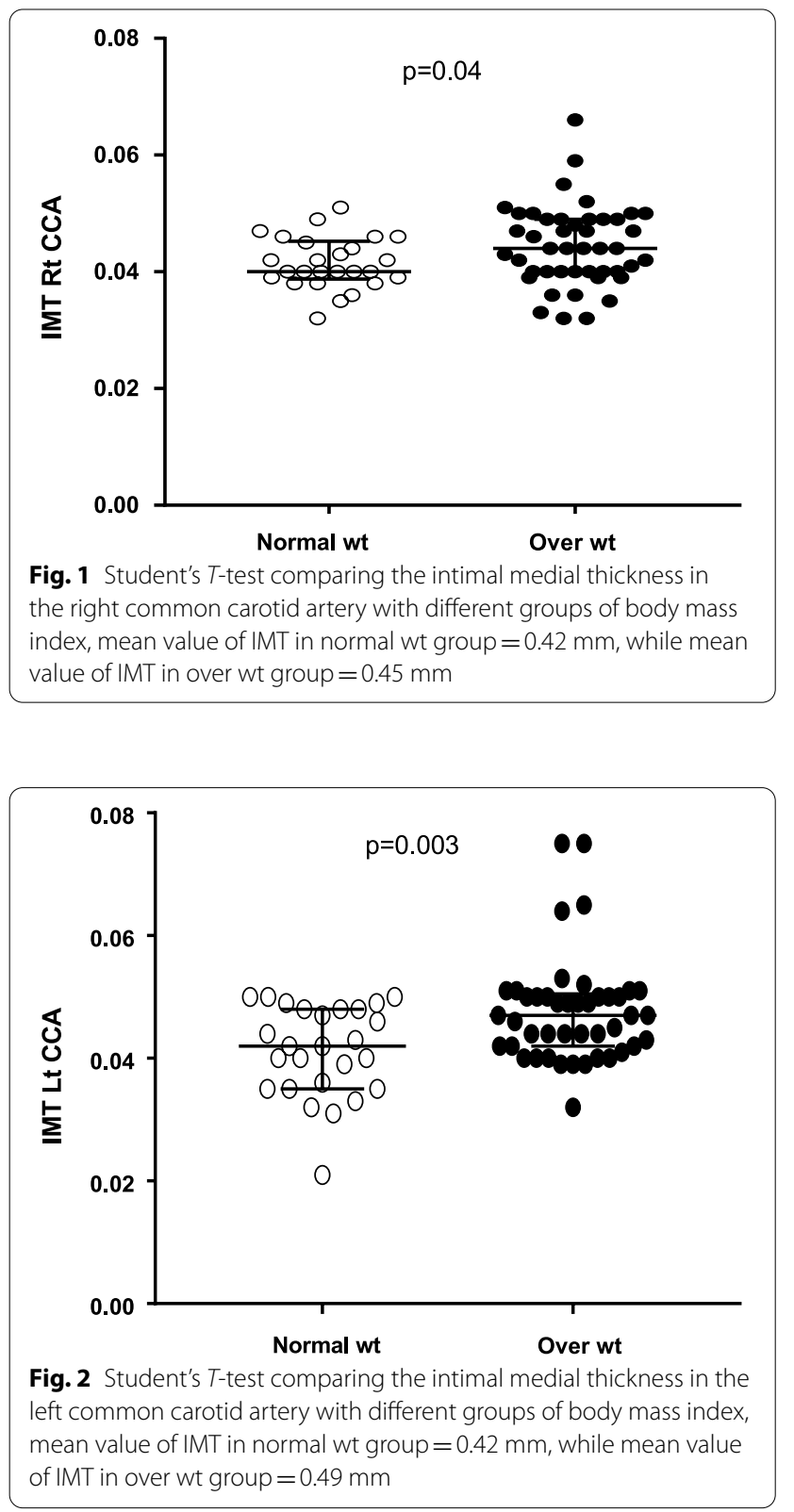

Furthermore, it was found that peak systolic velocity on the left common carotid arteries showed inverse relation to increased BMI $(r=-0.3, P$ value $<0.008)$. Although negative trend was observed on the right side, there was no significant correlation on the right side with BMI increases (Figs. 3 and 4).

\section{Discussion}

Duplex color scan is considered an important diagnostic tool for assessment of subtle carotid atherosclerotic disease using fundamental parameters especially the
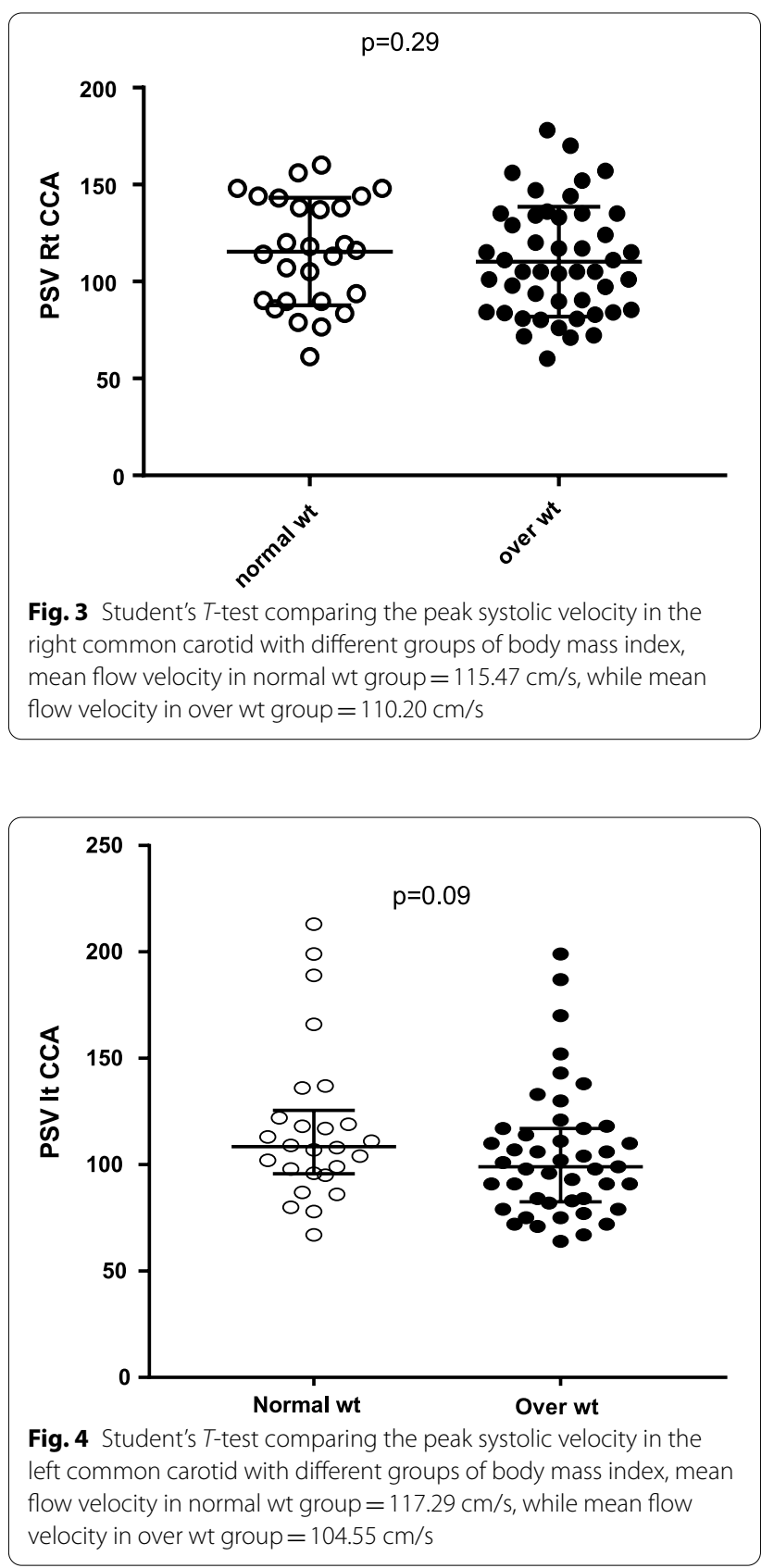

carotid wall thickness which represents an important risk factor for stroke; $30-60 \%$ of patients with stoke have plaques or at least thickened intima [2].

In our study, the intimal medial carotid thickness was significantly higher in overweight group compared to normal individuals with significant $P$ value $(P$ value $<0.05$; Figs. 1 and 2 ). In this study, results were in alignment with outcomes reported by other studies [14-18] that explained the obesity-related dyslipidemia could contribute to the process of atherosclerosis can 
affect progressively the vessel luminal diameter as well as the arterial wall thickness.

In addition, our study reported that the peak systolic velocity in the common carotid arteries declines as the body mass index increases (inversely related). Which could be due to the decrease in the elasticity of the vessels that normally occur as a part of the aging process and the increase of the intimal medial thickness [19-24]. Also, PSV decline was reported with increasing the dyslipidemia that presents with obesity.

Although lower PSV figures were observed in the overweight group, no significant difference was reported when compared to those with normal BMI in our study which is different from that reported with previous studies which showed significant difference between obese and non-obese individuals [25]. This can be attributed to higher number of normal BMI population in our study. Obesity-related arterial changes led to narrowing of the arterial lumen then thickening of the intima which is considered the early stage of atherosclerosis. Consequently, this ends eventually in a full-blown picture of atherosclerosis with plaque formation and subsequent increased risk of cerebrovascular accidents [24, 26].

There were some limitations in this study including its prospective and nonrandomized nature, in addition to the small number of populations included in this study.

\section{Conclusion}

Carotid duplex can detect early changes in the carotid system caused by, especially intimal medial thickness and peak systolic velocity.

Our study demonstrates the importance of the carotid Doppler imaging as a cheap, non-invasive scanning tool for early diagnosis of carotid system diseases and stenosis and early management or even referral for more specific investigatory tool to confirm diagnosis and sequential starting management.

\footnotetext{
Abbreviations

BMI: Body mass index; CCA: Common carotid artery; CW: Doppler Colored Doppler; CBIF: Carotid bifurcation; DUS: Doppler ultrasonography; ECA: External carotid artery; EDV: End-diastolic velocity; ICA: Internal carotid artery; IMT: Intimal medial thickness; Kg/m²: Kilogram/meter²; LT: Left; LD: Luminal diameter; MCA: Middle cerebral artery; MRI: Magnetic resonance imaging; PSV: Peak systolic velocity; RT: Right.
}

\section{Acknowledgements}

Not applicable.

\section{Authors' contributions}

TR: supervisor and data analysis. MG: acquisition of data, data analysis, writing of the manuscript. KO: acquisition of data, study design, and editing of the manuscript. All authors read and approved the final manuscript.

\section{Funding}

Not applicable (no funding received in this study).

\section{Availability of data and materials}

The datasets used and/or analyzed during the current study are available from the corresponding author on reasonable request.

\section{Declarations}

Ethics approval and consent to participate

This study protocol was approved by the ethical committee at the Faculty of Medicine, Assuit University, in October 2017.IRB local approval number: 17100306.All participant patients or their 1st degree of relatives gave informed written consent for the participation in the study before assessment. All patients' data were kept confidentially.

\section{Consent for publication}

Not applicable.

\section{Competing interests}

The authors declare that they have no competing interests in this section.

Received: 14 October 2020 Accepted: 6 August 2021

Published online: 28 August 2021

\section{References}

1. Rothwell P, Coull A, Silver L, Fairhead J, Giles M, Lovelock C, et al. Population-based study of event-rate, incidence, case fatality, and mortality for all acute vascular events in all arterial territories (Oxford Vascular Study). The Lancet. 2005;366(9499):1773-83.

2. Bluth El, McVay L 3rd, Merritt C, Sullivan MA. The identification of ulcerative plaque with high resolution duplex carotid scanning. J Ultrasound Med. 1988;7(2):73-6.

3. lemolo F, Martiniuk A, Steinman DA, Spence JD. Sex differences in carotid plaque and stenosis. Stroke. 2004;35(2):477-81.

4. Lfotouh A, Soliman L, Mansour E, Farghaly M, El Dawaiaty A. Central obesity among adults in Egypt: prevalence and associated morbidity. EMHJ-East Mediterr Health J. 2008;14(1):57-68.

5. Obesity and overweigh. https://www.who.int/news-room/fact-sheets/ detail/obesity-and-overweight. Accessed 14 Oct 2020.

6. Bonita R, Winkelmann R, Douglas KA, de Courten M. The WHO stepwise approach to surveillance (STEPS) of noncommunicable disease risk factors. In: McQueen DV, Puska P, editors. Global behavioral risk factor surveillance. Berlin: Springer; Boston, MA. 2003. https://doi.org/10.1007/ 978-1-4615-0071-1_3

7. Mei Z, Grummer-Strawn LM, Pietrobelli A, Goulding A, Goran MI, Dietz WH. Validity of body mass index compared with other body-composition screening indexes for the assessment of body fatness in children and adolescents. Am J Clin Nutr. 2002;75(6):978-85.

8. Eckel RH, Grundy SM, Zimmet PZ. The metabolic syndrome. The Lancet. 2005;365(9468):1415-28.

9. Kappus RM, Fahs CA, Smith D, Horn GP, Agiovlasitis S, Rossow L, et al. Obesity and overweight associated with increased carotid diameter and decreased arterial function in young otherwise healthy men. Am J Hypertens. 2014;27(4):628-34

10. Renna NF, de las Heras N, Miatello RM. Pathophysiology of vascular remodeling in hypertension. Int J Hypertens. 2013;2013:808353.

11. Howard G, Sharrett AR, Heiss G, Evans GW, Chambless LE, Riley WA, et al. Carotid artery intimal-medial thickness distribution in general populations as evaluated by B-mode ultrasound ARIC Investigators. Stroke. 1993;24(9):1297-304

12. Coll B, Feinstein SB. Carotid intima-media thickness measurements: techniques and clinical relevance. Curr Atheroscler Rep. 2008;10(5):444-50.

13. Baroncini LAV, de Castro SL, Pecoits FR. Carotid intima-media thickness and carotid plaque represent different adaptive responses to traditional cardiovascular risk factors. IJC Heart Vasc. 2015;9:48-51.

14. Özdemir H, Artas H, Serhatlioglu S, Ogur E. Effects of overweight on luminal diameter, flow velocity and intima-media thickness of carotid arteries. Diagn Interv Radiol. 2006;12(3):142.

15. Bots ML, Evans GW, Riley WA, Grobbee DE. Carotid intima-media thickness measurements in intervention studies: design options, 
progression rates, and sample size considerations: a point of view. Stroke. 2003;34(12):2985-94.

16. Burke AP, Kolodgie FD, Farb A, Weber D, Virmani R. Morphological predictors of arterial remodeling in coronary atherosclerosis. Circulation. 2002;105(3):297-303.

17. Rexrode KM, Hennekens CH, Willett WC, Colditz GA, Stampfer MJ, Rich-Edwards JW, et al. A prospective study of body mass index, weight change, and risk of stroke in women. JAMA. 1997;277(19):1539-45.

18. Asaleye AA, Braimoh KT, Oyinloye Ol, Asaleye CM, Omisore AD. Variation of carotid intima media thickness with body mass index in healthy adults of black African descent. J Ultrasound Med. 2019;38(1):123-30.

19. Krejza J, Szydlik P, Liebeskind DS, Kochanowicz J, Bronov O, Mariak Z, et al. Age and sex variability and normal reference values for the VMCANICA index. Am J Neuroradiol. 2005;26(4):730-5.

20. Forteza AM, Krejza J, Koch S, Babikian VL. Ultrasound imaging of cerebrovascular disease. In: Babikian VL, Wechsler L, Higashida RT, edtors. Imaging cerebrovascular disease. Philadelphia: Butterworth-Heinemann; 2003, pp. $3-35$.

21. Krejza J, Arkuszewski M, Kasner SE, Weigele J, Ustymowicz A, Hurst RW, et al. Carotid artery diameter in men and women and the relation to body and neck size. Stroke. 2006;37(4):1103-5.

22. Hansen F, Mangell P, Sonesson B, Länne T. Diameter and compliance in the human common carotid artery — variations with age and sex. Ultrasound Med Biol. 1995;21(1):1-9.
23. Sass C, Herbeth B, Chapet O, Siest G, Visvikis S, Zannad F. Intima-media thickness and diameter of carotid and femoral arteries in children, adolescents and adults from the Stanislas cohort: effect of age, sex, anthropometry and blood pressure. J Hypertens. 1998;16(11):1593-602.

24. Scheel P, Ruge C, Schöning M. Flow velocity and flow volume measurements in the extracranial carotid and vertebral arteries in healthy adults: reference data and the effects of age. Ultrasound Med Biol. 2000;26(8):1261-6.

25. Pam S, Dakok K, Chagok N, Gadong E, Sirisena U. Comparative study on luminal diameter, blood flow velocity and intima media thickness of carotid arteries in obese and non-obese humans. 2015.

26. Wang H-B, Laskowitz DT, Dodds JA, Xie G-Q, Zhang P-H, Huang Y-N, et al. Peak systolic velocity measurements with transcranial Doppler ultrasound is a predictor of incident stroke among the general population in China. PLoS ONE. 2016;11(8):e0160967.

\section{Publisher's Note}

Springer Nature remains neutral with regard to jurisdictional claims in published maps and institutional affiliations.

\section{Submit your manuscript to a SpringerOpen ${ }^{\circ}$ journal and benefit from:}

- Convenient online submission

- Rigorous peer review

- Open access: articles freely available online

- High visibility within the field

- Retaining the copyright to your article

Submit your next manuscript at $\boldsymbol{\Delta}$ springeropen.com 